\title{
On the estimation of lightning peak currents from measured fields using lightning location systems
}

\author{
F. Rachidi ${ }^{\text {a,* }}$, J.L. Bermudez ${ }^{\text {a }}$, M. Rubinstein ${ }^{\mathrm{b}}$, V.A. Rakov ${ }^{\mathrm{c}}$ \\ ${ }^{a}$ Power Systems Laboratory, Swiss Federal Institute of Technology, EPFL-LRE, Lausanne, Switzerland \\ ${ }^{\mathrm{b}}$ University of Applied Sciences of Western Switzerland, Yverdon, Switzerland \\ ${ }^{\mathrm{c}}$ Department of Electrical and Computer Engineering, University of Florida, Gainesville, FL 32611, USA
}

\begin{abstract}
Although, due to the high variability of key parameters such as the return-stroke speed, it is impossible to determine the lightning current accurately from the remotely measured electric or magnetic field for a given event, we show in this paper that, for an assumed return-stroke model, the statistical estimation (e.g. in terms of mean values and standard deviations) is possible. We show additionally that for the transmission line (TL) model, the equation permitting to infer the mean value of the return-stroke current from the mean value of electric or magnetic field and the mean value of speed has the same functional form as the well-known TL current - far field relationship. This result gives to some extent a theoretical justification to the use of lightning location systems to infer parameters of lightning current statistical distributions from measured fields alone.
\end{abstract}

(C) 2004 Elsevier B.V. All rights reserved.

Keywords: Lightning current; Remote field measurements; Statistical evaluation

\section{Introduction}

The problem of the estimation of lightning return-stroke currents from distant electromagnetic field measurements has received an increased attention due to the widespread use of lightning location systems (LLS). Due to the enormous amount of data that can be gathered by means of LLS, such systems represent a promising source of experimental data to be used for the development of standards related to the protection of power and telecommunication systems against lightning.

\footnotetext{
*Corresponding author.

E-mail address: farhad.rachidi@epfl.ch (F. Rachidi).
} 
Estimates of lightning peak currents from measured lightning electromagnetic fields are obtained by way of empirical [1-3] or theoretical [4] equations relating the electromagnetic field to the lightning current.

There is, however, an inherent difficulty in extracting lightning current parameters from LLS-measured electromagnetic fields since unknown parameters - such as the return-stroke speed - along with possible current reflections (in the case of strikes to a tall object) within the strike object affect the lightning current inferred from distant electromagnetic fields $[5,6]$. Various approaches to the estimation of parameters of peak current distributions from parameters of measured peak field distributions are discussed in [3].

In this paper, we present the theoretical basis for the statistical estimation of the lightning current from distant field measurements.

\section{Estimation of lightning current from distant electromagnetic field}

\subsection{Deterministic approach}

Expressions relating far electromagnetic fields and associated return-stroke currents at the channel base have been derived in the literature for various lightning return-stroke models [4]. The use of such relations permits the estimation of channel base currents of return-strokes, and the estimation of not-directly measurable parameters of the models [4]. Appendix A summarizes the equations relating far electric fields to channel base currents according to various return-stroke models. It can be seen that all these equations involve a certain number of parameters, in particular the return-stroke speed $v$, which, in most practical cases, are unknown. In other words, to infer the lightning current from its associated distant electric or magnetic field, one has to assume the value for the return-stroke speed. This speed changes, however, from one stroke to another and, as a result, exhibits significant statistical variation (e.g. [2,7,8]). It follows from the far-field-channel base current relations that an error in the estimation of return-stroke speed would result in practically the same amount of error in the inferred channel-base current (see also [9]). In fact, distant electric and magnetic field peaks are determined as much by return-stroke speeds as they are by return-stroke current peaks.

\subsection{Statistical approach}

We will consider the return-stroke current peak $I$, the return-stroke speed $v$, and the distant electric field peak $E$ as random variables and we will assume that the spatial-temporal distribution of the lightning current along the channel is as predicted by the transmission line (TL) model [10]. The TL model has been adopted here only for its simplicity and its ability to reproduce electromagnetic field peaks with reasonable accuracy, as shown in Ref. [1,11]. However, it should be emphasized that the developments presented in the present paper 
are also applicable to other, more complex return-stroke models (see, for example, [12]).

According to the TL model, the current peak is related to the far-field peak and to the return-stroke speed (assuming that $v=$ const, ${ }^{1}$ the ground is perfectly conducting, and the return-stroke front has not reached the top of the channel) through the following expressions [13]:

$$
\begin{aligned}
& E=\frac{v}{2 \pi \varepsilon_{\mathrm{o}} c^{2} r} I, \\
& I=2 \pi \varepsilon_{\mathrm{o}} c^{2} r \frac{E}{v},
\end{aligned}
$$

where $r$ is the horizontal distance between the lightning channel and the observation point, and $c$ is the speed of light. Note that the usual minus sign does not appear in Eq. (1) because we are interested in magnitudes only.

If the probability density functions (PDF) associated with the random variables $E$ and $v$ are known, then it is possible to obtain the PDF associated with the current $I$. In general, given the random variables $x, y$, and $z=g(x, y)$, the PDF of $z$ can be expressed in terms of PDFs of $x$ and $y$ [14]:

$$
\begin{aligned}
f(z) & =\int_{-\infty}^{\infty} f\left(g^{-1}(z, y), y\right)\left|\frac{\partial g^{-1}(z, y)}{\partial z}\right| \mathrm{d} y \\
& =\int_{-\infty}^{\infty} f\left(x, g^{-1}(x, z)\right)\left|\frac{\partial g^{-1}(x, z)}{\partial z}\right| \mathrm{d} x .
\end{aligned}
$$

In many practical cases, however, the exact PDFs of the involved random variables are unknown. In those cases, it is still possible to obtain estimates of the expectation and dispersion of $z$, starting from those of $x$ and $y$. Indeed, expanding the function $g$ in a series about the point $\left(\eta_{x}, \eta_{y}\right)$, where $\eta_{x}, \eta_{y}$ are the mean values of $x$ and $y$, respectively, the mean value and variance of $z$ can be estimated as [14]

$$
\begin{aligned}
& \eta_{z} \cong g\left(\eta_{x}, \eta_{y}\right)+\frac{1}{2}\left(\frac{\partial^{2} g\left(\eta_{x}, \eta_{y}\right)}{\partial x^{2}} \sigma_{x}^{2}+2 \frac{\partial^{2} g\left(\eta_{x}, \eta_{y}\right)}{\partial x \partial y} \rho_{x y} \sigma_{x} \sigma_{y}+\frac{\partial^{2} g\left(\eta_{x}, \eta_{y}\right)}{\partial y^{2}} \sigma_{y}^{2}\right), \\
& \sigma_{z}^{2} \cong\left(\frac{\partial g\left(\eta_{x}, \eta_{y}\right)}{\partial x}\right) \sigma_{x}^{2}+2 \frac{\partial g\left(\eta_{x}, \eta_{y}\right)}{\partial x} \frac{\partial g\left(\eta_{x}, \eta_{y}\right)}{\partial y} \rho_{x y} \sigma_{x} \sigma_{y}+\left(\frac{\partial g\left(\eta_{x}, \eta_{y}\right)}{\partial y}\right)^{2} \sigma_{y}^{2}
\end{aligned}
$$

where $\sigma_{x}, \sigma_{y}, \sigma_{z}$ are the standard deviations of $x, y$ and $z$, respectively, and $\rho_{x y}$ is the correlation coefficient between $x$ and $y$, given by

$$
\rho_{x y}=\frac{\eta_{x y}-\eta_{x} \eta_{y}}{\sigma_{x} \sigma_{y}}
$$

\footnotetext{
${ }^{1}$ The return-stroke speed varies in general along the return-stroke channel. Since we are considering early times during which current and field peaks occur, the value of the return-stroke speed corresponds to its value at the bottom of the channel (below $500 \mathrm{~m}$ or so). Most of the measured return-stroke speeds found in the literature are averaged over some lowest hundreds of meters.
} 
Applying Eqs. (4) and (5) to Eq. (1), and after straightforward mathematical manipulations, we obtain

$$
\eta_{E} \cong \frac{1}{2 \pi \varepsilon_{0} c^{2} r} \eta_{v} \eta_{I}+\frac{1}{2 \pi \varepsilon_{0} c^{2} r} \rho_{v I} \sigma_{v} \sigma_{I}
$$

and

$$
\sigma_{E}^{2} \cong\left(\frac{1}{2 \pi \varepsilon_{0} c^{2} r} \eta_{I}\right)^{2} \sigma_{v}^{2}+\left(\frac{1}{2 \pi \varepsilon_{0} c^{2} r} \eta_{v}\right)^{2} \sigma_{I}^{2}+\frac{1}{\pi \varepsilon_{0} c^{2} r} \frac{1}{2 \pi \varepsilon_{0} c^{2} r} \eta_{I} \eta_{v} \rho_{v I} \sigma_{I} \sigma_{v}
$$

Neglecting any correlation between current peak and return-stroke speed (see [23] for a discussion of this issue), Eqs. (7) and (8) become, respectively

$$
\begin{aligned}
& \eta_{E} \cong \frac{1}{2 \pi \varepsilon_{\mathrm{o}} c^{2} r} \eta_{v} \eta_{I} \\
& \sigma_{E}^{2} \cong\left(\frac{1}{2 \pi \varepsilon_{\mathrm{o}} c^{2} r} \eta_{I}\right)^{2} \sigma_{v}^{2}+\left(\frac{1}{2 \pi \varepsilon_{\mathrm{o}} c^{2} r} \eta_{v}\right)^{2} \sigma_{I}^{2} .
\end{aligned}
$$

It is interesting to observe that Eq. (9) has the same mathematical form as Eq. (1), where the values for $E, v$, and $I$ are simply replaced by the respective mean values $\eta_{E}$, $\eta_{v}$, and $\eta_{I}$. This result gives to some extent a theoretical justification to the use of LLS to infer statistical parameters of the lightning current from measured fields alone. In other words, although it seems impossible to obtain a reasonably accurate estimate of the return-stroke current from distant field measurements for a single event without prior knowledge of the return-stroke speed, this could be done statistically, in terms of mean value and standard deviation, using field measurements acquired by LLS, provided that statistical data for the return-stroke speed are available from independent measurements and are not varying much within the area covered by the LLS.

\section{Comparison with experimental data}

In order to test the validity of the derived equations, we will use simultaneous measurements of return-stroke current, electric field at $5 \mathrm{~km}$, and return-stroke speed associated with triggered lightning return-strokes and reported by Willett et al. in Ref. [1]. Table 1 summarizes values for return-stroke current peak, electric field (essentially radiation) peak at $5 \mathrm{~km}$, and photographically measured two-dimensional return-stroke speed for 17 events. The corresponding mean values, standard deviations, and correlation coefficients are given in Table 2.

Let us assume that the channel-base current is unknown. Inserting statistical parameters associated with field and return-stroke speed into Eqs. (7) and (8), the following values can be calculated for the return-stroke current:

$$
\eta_{I}=18.5 \mathrm{kA} \text { and } \sigma_{I}=7.0 \mathrm{kA}
$$

which are in very good agreement with values (see Table 2) determined from measurements presented in Table 1 . 
Table 1

Simultaneous measurements of channel-base current peak, electric field peak at $5 \mathrm{~km}$, and return-stroke speed associated with 17 rocket-triggered lightning return-strokes (adapted from Willett et al. [1])

\begin{tabular}{llrl}
\hline Flash/stroke & $I(\mathrm{kA})$ & $E$ at $5 \mathrm{~km}(\mathrm{~V} / \mathrm{m})$ & $v_{2-\mathrm{D}}\left(10^{8} \mathrm{~m} / \mathrm{s}\right)$ \\
\hline $8705 / 1$ & 8.2 & 76 & 1.8 \\
$8705 / 3$ & 7.7 & 64 & 1.6 \\
$8705 / 5$ & 10.3 & 80 & 1.7 \\
$8705 / 6$ & 11.6 & 84 & 1.9 \\
$8715 / 9$ & 33 & 206 & 1.4 \\
$8715 / 10$ & 15.6 & 88 & 1.4 \\
$8725 / 1$ & 20.3 & 109 & 1.6 \\
$8725 / 2$ & 16.7 & 84 & 1.5 \\
$8725 / 3$ & 43 & 196 & 1.7 \\
$8725 / 5$ & 11.7 & 60 & 1.4 \\
$8726 / 2$ & 26.9 & 174 & 1.2 \\
$8726 / 3$ & 16.4 & 95 & 1.4 \\
$8726 / 4$ & 143 & 1.4 \\
$8728 / 10$ & 22.4 & 144 & 1.4 \\
$8728 / 1$ & 26.9 & 88 & 1.4 \\
$8732 / 1$ & 16.1 & 126 & 1.5 \\
$8732 / 2$ & 18.0 & 97 & 1.6 \\
\hline
\end{tabular}

Table 2

Statistical parameters for the data presented in Table 1

\begin{tabular}{|c|c|c|c|}
\hline Parameter & $I(\mathrm{kA})$ & $v_{2-\mathrm{D}}\left(10^{8} \mathrm{~m} / \mathrm{s}\right)$ & $E(\mathrm{~V} / \mathrm{m})$ \\
\hline Min. value & 7.7 & 1.2 & 60 \\
\hline Max. value & 43 & 1.9 & 206 \\
\hline Mean value & 18.9 & 1.5 & 112.6 \\
\hline Standard deviation & 9.3 & 0.18 & 45.1 \\
\hline$\rho_{I v}$ & \multirow{2}{*}{\multicolumn{2}{|c|}{0.0144}} & \\
\hline$\rho_{E v}$ & & & 0.0268 \\
\hline
\end{tabular}

Similarly, starting from statistical parameters for current and return-stroke speed, one can obtain from Eqs. (7) and (8) the following values for the electric field:

$$
\eta_{E}=113.4 \mathrm{~V} / \mathrm{m} \text { and } \sigma_{E}=57.5 \mathrm{~V} / \mathrm{m}
$$

which, again, are in excellent agreement with the values in Table 2 determined from data presented in Table 1.

Note that, since the correlation coefficients $\rho_{I v}$ and $\rho_{E v}$ are very small, the use of Eqs. (9) and (10) instead of the more general equations (7) and (8) does not introduce significant errors. This is an important observation since it suggests that no knowledge (usually unavailable) of the correlation coefficients is necessary. 
The theory presented in this paper is best suited for parameters that are described by normal distributions. On the other hand, the peak current and peak field are known to be characterized by log-normal distributions. Work is in progress to develop specific expressions assuming log-normal distributions for current and field [3].

\section{Summary}

The estimation of lightning return-stroke currents from distant electromagnetic field measurements is an important problem that has received an increased attention due to the growing use of lightning location systems. However, the high variability of key parameters, such as the return-stroke speed, makes it impossible to obtain a reasonably accurate estimate of lightning current from the distant field measurement for an individual event. We show in this paper that the statistical estimation (e.g. in terms of mean values and standard deviations) is possible. We show additionally that for the transmission line (TL) model, the equation permitting to infer the mean value of the return-stroke current from the mean values of field and speed has the same functional form as the well-known TL current-far field relationship. This result gives, to some extent, a theoretical justification to the use of LLS to infer statistical parameters of lightning current from measured fields alone, assuming that the return-stroke speed does not vary much within the area covered by the LLS.

\section{Acknowledgements}

This research has been financially supported by the Swiss National Science Foundation (Grants 20-56862.99 and 2000-068147) and by the US National Science Foundation (Grant ATM 0003994). Special thanks are due to C.A. Nucci and V. Shostak for their valuable comments on the manuscript.

\section{Appendix A. Equations relating far electric field to channel-base current according to various engineering return-stroke models}

$B G$ (Bruce and Golde) model:

Spatial-temporal distribution [15],

$$
i\left(z^{\prime}, t\right)= \begin{cases}i(0, t), & z^{\prime} \leqslant v t \\ 0, & z^{\prime}>v t\end{cases}
$$

Far electric field-channel-base current link [16]

$$
i(0, t)=-\frac{2 \pi \varepsilon_{\mathrm{o}} c^{2} r}{v t} \int_{0}^{t} E_{z}^{\mathrm{far}}(r, \tau+r / c) \mathrm{d} \tau .
$$


TL (transmission line) model:

Spatial-temporal distribution [10]

$$
i\left(z^{\prime}, t\right)= \begin{cases}i\left(0, t-z^{\prime} / v\right), & z^{\prime} \leqslant v t \\ 0, & z^{\prime}>v t\end{cases}
$$

Far electric field-channel-base current link [13]

$$
i(0, t)=-\frac{2 \pi \varepsilon_{\mathrm{o}} c^{2} r}{v} E_{z}^{\mathrm{far}}(r, t+r / c) .
$$

TCS (traveling current source) model:

Spatial-temporal distribution [17]

$$
i\left(z^{\prime}, t\right)= \begin{cases}i\left(0, t+z^{\prime} / v\right), & z^{\prime} \leqslant v t \\ 0, & z^{\prime}>v t\end{cases}
$$

Far electric field-channel-base current link [18]

$$
E_{z}^{\mathrm{far}}(r, t+r / c)=-\frac{1}{2 \pi \varepsilon_{0} c r}[k i(0, k t)-i(0, t)],
$$

where $k=(1+v / c)$.

MTLL (modified transmission line, linear current decay with height) model:

Spatial-temporal distribution [9]

$$
i\left(z^{\prime}, t\right)= \begin{cases}\left(1-\frac{z^{\prime}}{H}\right) i\left(0, t-z^{\prime} / v\right), & z^{\prime} \leqslant v t, \\ 0, & z^{\prime}>v t,\end{cases}
$$

where $H$ is the height of the lightning channel.

After mathematical developments similar to those for MTLE model in Ref. [19], the following expression relating far electric field to the channel-base current can be derived for MTLL model [20]:

$$
\frac{\mathrm{d} E_{z}^{\mathrm{far}}(r, t)}{\mathrm{d} t}=-\frac{v}{2 \pi \varepsilon_{\mathrm{O}} c^{2} r}\left[\frac{\mathrm{d} i(t-r / c)}{\mathrm{d} t}-\frac{v}{H} i(t-r / c)\right] .
$$

MTLE (modified transmission line, exponential current decay with height) model:

Spatial-temporal distribution [21]

$$
i\left(z^{\prime}, t\right)= \begin{cases}\exp \left(-z^{\prime} / \lambda\right) i\left(0, t-z^{\prime} / v\right), & z^{\prime} \leqslant v t \\ 0, & z^{\prime}>v t\end{cases}
$$

Far electric field-channel-base current link [19]

$$
\frac{\mathrm{d} i(0, t)}{\mathrm{d} t}=-2 \pi \varepsilon_{\mathrm{o}} c^{2} r\left[\frac{E_{z}^{\mathrm{far}}(r, t+r / c)}{\lambda}+\frac{1}{v} \frac{\mathrm{d} E_{z}^{\mathrm{far}}(r, t+r / c)}{\mathrm{d} t}\right] \quad t<\frac{H}{v}+\frac{r}{c} .
$$


DU (Diendorfer-Uman) model:

Spatial-temporal distribution [22]

$$
i\left(z^{\prime}, t\right)=i\left(0, t+z^{\prime} / c\right)-i\left(0, \frac{z^{\prime}}{v}+\frac{z^{\prime}}{c}\right) \exp \left[-\left(t-\frac{z^{\prime}}{v}\right) / \tau_{\mathrm{D}}\right] .
$$

Far electric field-channel-base current link [19]

$$
\begin{aligned}
& E_{z}^{\mathrm{far}}(r, t+r / c)+\tau_{\mathrm{D}} \frac{\mathrm{d} E_{z}^{\mathrm{far}}(r, t+r / c)}{\mathrm{d} t} \\
& \quad=-\frac{1}{2 \pi \varepsilon_{0} c r}\left\{k i(0, k t)-i(0, t)+\tau_{\mathrm{D}} \frac{\mathrm{d}}{\mathrm{d} t}[i(0, k t)-i(0, t)]\right\} .
\end{aligned}
$$

\section{References}

[1] J.C. Willett, J.C. Bailley, V.P. Idone, A. Eybert-Berard, L. Barret, Submicrosecond intercomparison of radiation fields and currents in triggered lightning return strokes based on the transmission-line model, J. Geophys. Res. 94 (1989) 13275-13286.

[2] V.A. Rakov, R. Thottappillil, M.A. Uman, On the empirical formula of Willett et al. relating lightning return stroke peak current and peak electric field, J. Geophys. Res. 97 (1992) 11527-11533.

[3] A.O. Lutz, K.M. Mashukov, V.A. Rakov, On estimation of lightning peak current distribution parameters from the distribution of field peaks, Trudy VGI, 72, Gidrometeoizdat, Moscow, 1989, pp. 31-35.

[4] F. Rachidi, R. Thottappillil, Determination of lightning currents from far electromagnetic fields, J. Geophys. Res. 98 (1993) 18315-18320.

[5] S. Guerrieri, C.A. Nucci, F. Rachidi, M. Rubinstein, On the influence of elevated strike objects on directly measured and indirectly estimated lightning currents, IEEE Trans. Power Delivery 13 (1998) 1543-1555.

[6] F. Rachidi, W. Janischewskyj, A.M. Hussein, C.A. Nucci, S. Guerrieri, B. Kordi, J.S. Chang, Current and electromagnetic field associated with lightning return strokes to tall towers, IEEE Trans. Electromag. Compatibility 43 (2001) 356-367.

[7] V.P. Idone, R.E. Orville, Lightning return stroke velocities in the Thunderstorm Research International Program (TRIP), J. Geophys. Res. 87 (1982) 4903-4915.

[8] D.M. Mach, W.D. Rust, Photoelectric return stroke velocity and peak current estimates in natural and triggered lightning, J. Geophys. Res. 94 (1989) 13,237-13,247.

[9] V.A. Rakov, A.A. Dulzon, Results of calculation of the electromagnetic fields of lightning discharges, Tekh. Elektrodinamika 1 (1987) 87-89.

[10] M.A. Uman, D.K. McLain, Magnetic field of lightning return stroke, J. Geophys. Res. 74 (1969) 6899-6910.

[11] R. Thottappillil, M.A. Uman, Comparison of lightning return stroke models, J. Geophys. Res. 98 (1993) 22903-22914.

[12] V.A. Rakov, M.A. Uman, Review and evaluation of lightning return stroke models including some aspects of their application, IEEE Trans. on Electromag. Compatibility 40 (4) (1998) 403-426.

[13] M.A. Uman, D.K. McLain, E.P. Krider, The electromagnetic radiation from a finite antenna, Am. J. Phys. 43 (1975) 33-38.

[14] A. Papoulis, Probability, Random Variables, and Stochastic Processes, 3rd Edition, McGraw-Hill, New York, 1991.

[15] C.E.R. Bruce, R.H. Golde, The lightning discharge, J. Inst. Electr. Eng. 88 (1941) 487-520.

[16] M.A. Uman, D.K. McLain, Lightning return stroke current from magnetic and radiation field measurements, J. Geophys. Res. 75 (1970) 5143-5147. 
[17] F. Heidler, Traveling current source model for LEMP calculation, in: Proceedings of the 6th International Symposium on Electromagnetic Compatibility, 1985, pp. 157-162.

[18] F. Heidler, Lightning electromagnetic pulse, Theorie und Messungen, Fakultät der Elektrotechnik, Universität der Bundeswehr, Munich 1987.

[19] F. Rachidi, C.A. Nucci, On the Master, Uman, Lin, Standler and the Modified Transmission Line lightning return stroke current models, J. Geophys. Res. 95 (1990) 20389-20394.

[20] F. Rachidi, J.L. Bermudez, Far field-current relation for MTLL model, EPFL, Internal Report, January 2001.

[21] C.A. Nucci, C. Mazzetti, F. Rachidi, M. Ianoz, On lightning return stroke models for LEMP calculations, presented at 19th International Conference on Lightning Protection, Graz, 1988.

[22] G. Diendorfer, M.A. Uman, An improved return stroke model with specified channel-base current, J. Geophys. Res. 95 (1990) 13621-13644.

[23] V.A. Rakov, M.A. Uman, Lightning: Physics and Effects, Cambridge University Press, Cambridge, 2003. 